The increase in the size of page has made it possible to achieve a more pleasing layout, and despite the use of a larger typeface and slight expansion of the text, there is a reduction in the number of pages. Unfortunately the improved appearance of the book is not enhanced by the photographic reproductions, the quality of some of which (for example Figs 1.10, 3.4 and 6.1) seems to have deteriorated progressively in succeeding editions.

The sequence of topics follows closely that of the second edition but the chapters have now been arranged in four sections: Structural and morphological aspects of development (Chapters 1 and 2); internal controls in plant development (Chapters 3-6); environmental control of development (Chapters 7-12); and, molecular and general aspects of differentiation (Chapter 13). Each section is prefaced by a short introduction and these serve to link the book together. The reading lists at the end of each chapter have been expanded considerably by the inclusion of some recent reviews and research publications.

However, much of the text remains un- altered and the claim of the publisher that the book has been "extensively re-written" is hardly justified. New material has been added here and there, particularly in the chapter dealing with the biochemistry of growth-regulating substances. Despite continuing research we are still a long way from understanding the mechanism of their action. In fact, as the authors recognize, the picture instead of becoming clarified seems to be getting more confused - a cause of some embarrassment to those of us who attempt to teach this subject to biologists.

Librarians who stocked up recently with copies of the second edition of this book will be relieved to learn that there is no great need to replace them with the new edition. Undergraduates who have little choice may begrudge the extra cost, but we will go on recommending the book to our students as the best overall introduction to the physiology of plant growth that is available at present.

James F. Sutcliffe is Professor of Plant Physiology at the University of Sussex.

\title{
Introducing whom to natural products?
}

\section{T.W. Goodwin}

Secondary Plant Metabolism. By Brian Vickery and Margaret L. Vickery. Pp.335. Hbk ISBN 0-333-27017-7; pbk ISBN0-33327018-5. (Macmillan Press, London/ University Park Press: 1981.) Hbk £25, $\$ 49.50 ; £ 12$.

IT is important not to criticize a book for not being what it was never intended to be. This is made difficult in the present instance because neither the authors nor the publishers give any hint of the type of reader the book is aimed at. What the book clearly is, is a full and up-to-date descriptive account at a rather simple level of the formation and metabolism of secondary plant products. On a slightly lower level, the function, uses, ecological interactions and chemosystematic properties are also discussed.

After an introductory chapter, which considers such topics as the differences between secondary and primary metabolites and how biosynthetic pathways are elucidated, the bulk of the book is devoted to essays on families of compounds which arise from basic precursors: these are sugars and sugar derivatives arising from the primary product of photosynthesis, considered to be glucose 6-phosphate; the various fatty acids produced from the acetate--malonate pathway and their incorporation into plant lipids and glycerides; polyketides from acetate which are mainly fungal rather than higher plant products; terpenoids derived from mevalonate; shikimic acid derivatives; compounds synthesized from two different fundamental units as exemplified by the flavonoids; porphyrins, purines and pyrimidines; compounds, including alkaloids, which are derived from various amino acids. A great deal of ground is covered and one's way about the concentrated information in the book is facilitated by three good indexes.

One can make a reasonable guess that this book is aimed at organic chemistry students studying a natural products course in their second year. It would be a satisfactory basis for such a course but probably lecturers would nowadays concentrate more on reaction types and reaction mechanisms rather than simply on biogenetic schemes. Certainly, stereochemical aspects would be given more prominence than they are afforded in the present text. The book would be useful to biochemists for basic information but not as a working text because, as the authors state, enzymology - the ultimate key to the explanation of all biosynthetic activity - is not included. In the same way it would be useful as a source book for botanists, agriculturalists and pharmacists.

This, then, is a good introductory book on natural products, although there is difficulty in visualizing exactly which academic slot it is intended to fill.

T.W. Goodwin is Johnston Professor of Biochemistry at the University of Liverpool.

\section{Botany for beginners}

\author{
Ralph S. Quatrano
}

Biology of Plants, 3rd Edn. By Peter H. Raven, Ray F. Evert and Helena Curtis. Pp.686. ISBN 0-87901-132-7. (Worth: 1981.) $\$ 19.95, £ 10.50$.

ONE OF the most widely adopted textbooks for introducing students to the plant sciences over the past several years has been Biology of Plants by Raven, Evert and Curtis. The new and much improved third edition of this popular text must still be considered as one of the best overall books of general botany.

Previous editions were clearly aimed at beginning courses for majors. Such courses would form the basis upon which more advanced courses, such as morphology, physiology and ecology, would build. The new edition is no exception. The depth and breadth are still sufficient for majors and it will be a good source book for any student of the biological sciences. However, the detail is not overwhelming and with the continual mention of applied and practical aspects of plant biology, as well as good chapter summaries, appendices for chemistry and classification, and a complete glossary, makes it a possible choice for non-major courses. Much of the condensing and rewriting in this edition have also helped to make it an attractive choice for a less rigorous introduction to botany. The length of the text, however, may be excessive for such courses, especially in view of the availability of other shorter, good "non-major" texts (see Nature 284, 91; 1980).

Although the sequence of topics presented in the text may not be followed, most botany instructors will find no problem in choosing specific chapters to fit their schedule. Several changes for the better in the organization of the third edition include moving the chapter on the chemistry of heredity to the section on genetics and evolution, more emphasis on the Cyanobacteria, and the treatment of the fungi as a group separate from the water and slime moulds (Protista). Several sections have been condensed (for example "Ecology", "Genetics and Evolution") without deleting important concepts, while others have been extensively updated and revised (for example "Growth Regulators", "Uptake and Transport").

The illustrations and diagrams are clear and the inclusion of colour plates for angiosperm anatomy in this edition will be helpful to students in the laboratory. The book will undoubtedly maintain its high ranking and competitiveness with other new editions of excellent, popular texts such as the sixth edition of Botany by Weier et al. (Wiley, 1982).

Ralph S. Quatrano is Professor of Botany and Instructor in General Botany and Biology Courses at Oregon State University, Corvallis, Oregon. 